\title{
Elder Abuse and Psychological Well-Being: A Systematic Review and Implications for Research and Policy - A Mini Review
}

\author{
XinQi Dong $^{\mathrm{a}}$ RuiJia Chen ${ }^{\mathrm{a}}$ E-Shien Chang ${ }^{\mathrm{a}}$ Melissa Simon $^{\mathrm{b}}$ \\ ${ }^{a}$ Chinese Health, Aging and Policy Program, Rush Institute for Healthy Aging, Rush University Medical Center, and \\ ${ }^{b}$ Northwestern University Medical Center, Chicago, III., USA
}

\section{Key Words}

Elder abuse $\cdot$ Psychological well-being $\cdot$ Aging $\cdot$ Chinese population

\begin{abstract}
Elder abuse and psychological distress are both important geriatric syndromes and are independently associated with premature morbidity and mortality. Despite recent advances, there has been little systematic exploration of the association between elder abuse and psychological distress. This systematic review synthesizes the qualitative and quantitative studies on the relationship between elder abuse and psychological distress, namely psychological distress as a risk factor and/or a consequence of elder abuse. Moreover, through this review, future research directions for elder abuse and psychological distress and their implications for practice and policy to improve the health and aging of vulnerable populations are also highlighted.
\end{abstract}

Copyright $\odot 2012$ S. Karger AG, Basel

\section{Introduction}

Elder abuse is a multifaceted and pervasive public health issue which includes physical, sexual and emotional abuse, financial exploitation and neglect (caregiver ne- glect and self-neglect). It is estimated that only a fraction of elder abuse cases actually comes to the attention of the adult protective services (APS) [1]. This is particularly alarming as the report of elder abuse to APS has been increasing in the last decade. Elder abuse in any form can be considered a stressful life event that may have negative effects on older adults' physical and mental health, as the literature suggests that elder abuse is associated with an increased risk of premature morbidity and mortality [2, 3]. In March 2011, the Senate Special Committee on Aging held a hearing on elder abuse entitled 'Justice for All: Ending Elder Abuse, Neglect and Exploitation'. Based on the Government Accountability Office report [4], victims and experts highlighted the lack of research, education, training and prevention strategies. In June 2010, the National Institute on Aging and the National Academies of Sciences hosted a state-of-science conference on elder abuse and highlighted the research progress as well as the vast gaps and recommended research priorities to advance the field of elder abuse.

Psychological well-being is critically important to health and aging, and psychological distress has been associated with morbidity and mortality. Evidence suggests that elder abuse is also associated with psychological distress, which particularly warrants more attention given that psychological distress in victims of elder abuse could be of crucial importance to the development of future in-

\section{KARGER}

Fax +41613061234

E-Mail karger@karger.ch

www.karger.com
(C) 2012 S. Karger AG, Basel

0304-324X/13/0592-0132\$38.00/0

Accessible online at:

www.karger.com/ger
XinQi Dong, MD, MPH

Chinese Health, Aging and Policy Program, Rush Institute for Healthy Aging

Rush University Medical Center, 1645 West Jackson, Suite 675

Chicago, IL 60612 (USA)

Tel. +1 312942 3350,E-Mail xinqi_dong@rush.edu 
tervention programs. In recent years, research studies and clinical cases have begun to document the associations between elder abuse and psychological distress. Despite old age and increased vulnerability possibly inherently lending themselves to negative emotional distress such as depression, anxiety and loneliness, elder abuse is a stressful life event that may lead to pronounced and sustained psychological distress in older adults. Whereas severe psychological distress experienced by older adults may be a result of abuse, less is known regarding the mechanisms that may increase the risks of abuse among older adults who have greater levels of psychological distress in the first place. Improved understanding of these relationships is critical to devise effective preventions and interventions among rapidly growing aging populations.

This systematic review synthesizes the qualitative and quantitative studies on our existing knowledge about the relationship between elder abuse and psychological distress, namely psychological distress as a risk factor associated with elder abuse and/or a consequence of elder abuse, and the effect of intervention in elder abuse with respect to psychological distress outcomes. Moreover, this review discusses future research directions relating to elder abuse and psychological distress as well as practical and policy implications for the field of elder abuse.

\section{Methods}

The purpose of this article is to provide a systematic review of the association between psychological distress and elder abuse and the effect of interventions and to provide directions for future research. A search was undertaken of medical and social science databases (e.g. PubMed, Medline, PsychInfo). We define psychological constructs as both self-perceived psychological distress as well as clinical diagnoses. Search terms included the following: depression, somatization, perceived happiness, loneliness, anxiety, posttraumatic stress disorder, perceived stress, suicidal ideation and attempts, self-esteem, paranoia and psychiatric disorders, including the presence of delusions and hallucinations. All literature found was published in English and came from a range of both US and international journals.

\section{Results}

\section{Psychological Distress as a Risk Factor Associated} with Elder Abuse

Due to the high prevalence and negative consequences of psychological distress, gerontological literature has started to address psychological distress as a risk factor for elder abuse (table 1). Currently, there is a great pau- city in our knowledge about the temporal relationship between psychological well-being and elder abuse through longitudinal studies. In most cross-sectional studies, risks for elder abuse are associated with two categories of factors, namely victim factors and perpetrator factors [5]. By studying the traits of abused older adults, researchers found that psychological distress has been associated with an increased risk of elder abuse [6,7]. Based on a well-characterized community-based cohort, clinical depression was significantly associated with elder abuse cases reported to APS [8]. In another clinical-based cohort studied by Dong et al. [9], loneliness was also associated with an increased risk of elder abuse.

In addition, the association between psychological distress and elder abuse is affected by sociodemographic characteristics. A study of the urban Chinese population found that among older adults with depressive distress, those who were older and had lower education levels may have an increased risk of elder abuse [10]. Moreover, gender may also have different effects on the relationship. Demented female patients were reported to be more likely to have a higher risk of experiencing neglect [11].

Compared to studies of victims, research on caregiver characteristics is scarce. Studies have reported that caregiver stress, anxiety and depression often result in a lack of confidence in caregiving ability and/or caregiving skills and thus potentially increase the use of abusive acts to manage these difficulties. After controlling for demographics, interpersonal relationship and illness severity, care recipients were still more likely to experience abuse when caregivers were at risk of clinical depression in the previous week [12]. Another study by Natan et al. [11] on the characteristics of care workers has shown that emotional fatigue and a feeling of depersonalization increase the risk of maltreatment. Due to the significant role of caregivers in elder abuse, more attention should be paid to caregiver stress and its effects on elder abuse.

\section{Psychological Consequences Associated with Elder Abuse}

Increased attention has been paid by healthcare practitioners to health outcomes of elder abuse, including the detrimental psychological consequences associated with elder abuse (table 2). Population-based studies found that older adults who experience elder abuse are faced with increased mortality risk [13]. Compared to physical health outcomes, the impact of elder abuse on psychological well-being may be even more devastating, and elders often take a long time to recover from the victimization [14]. However, there is a great paucity in our un- 


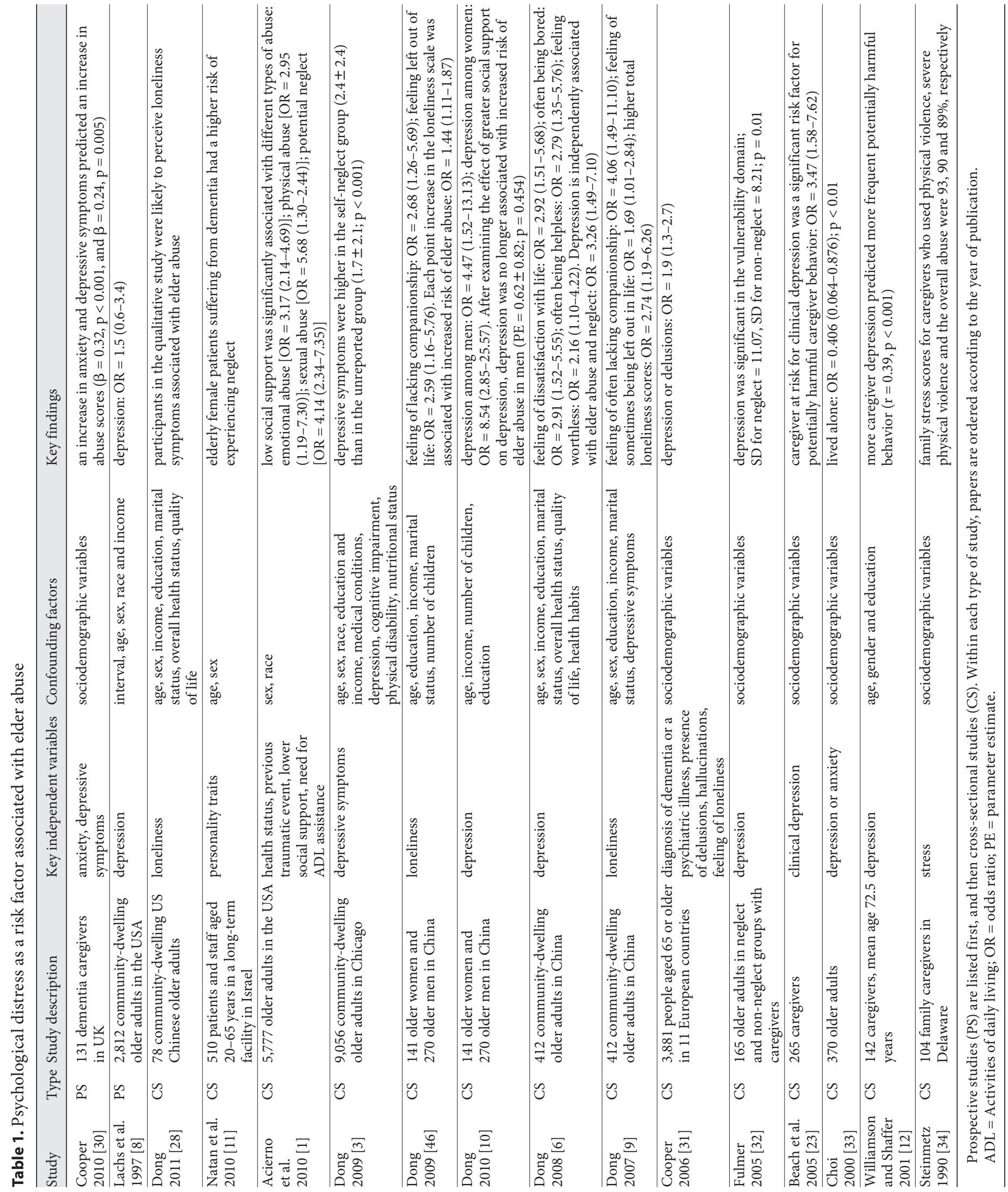




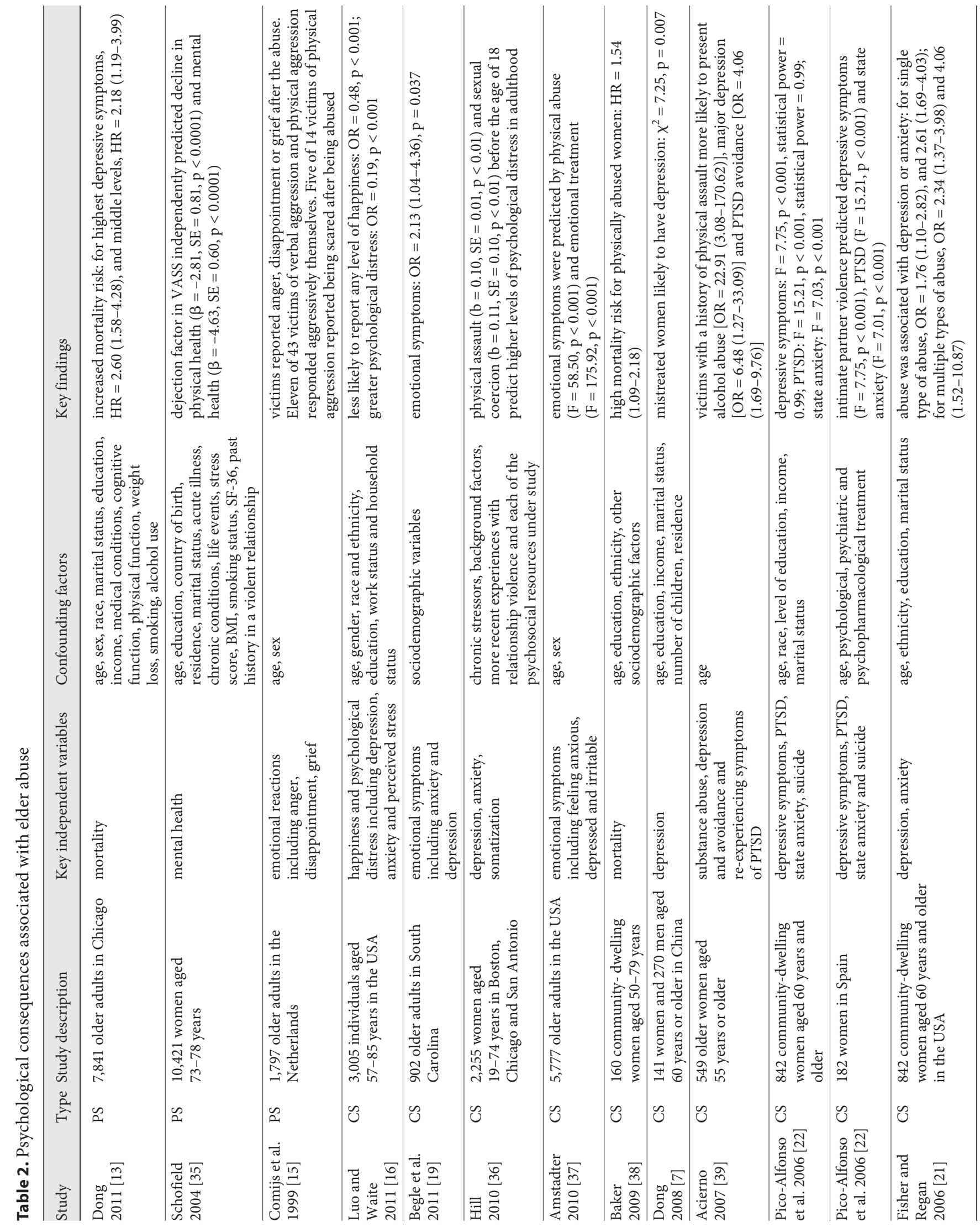




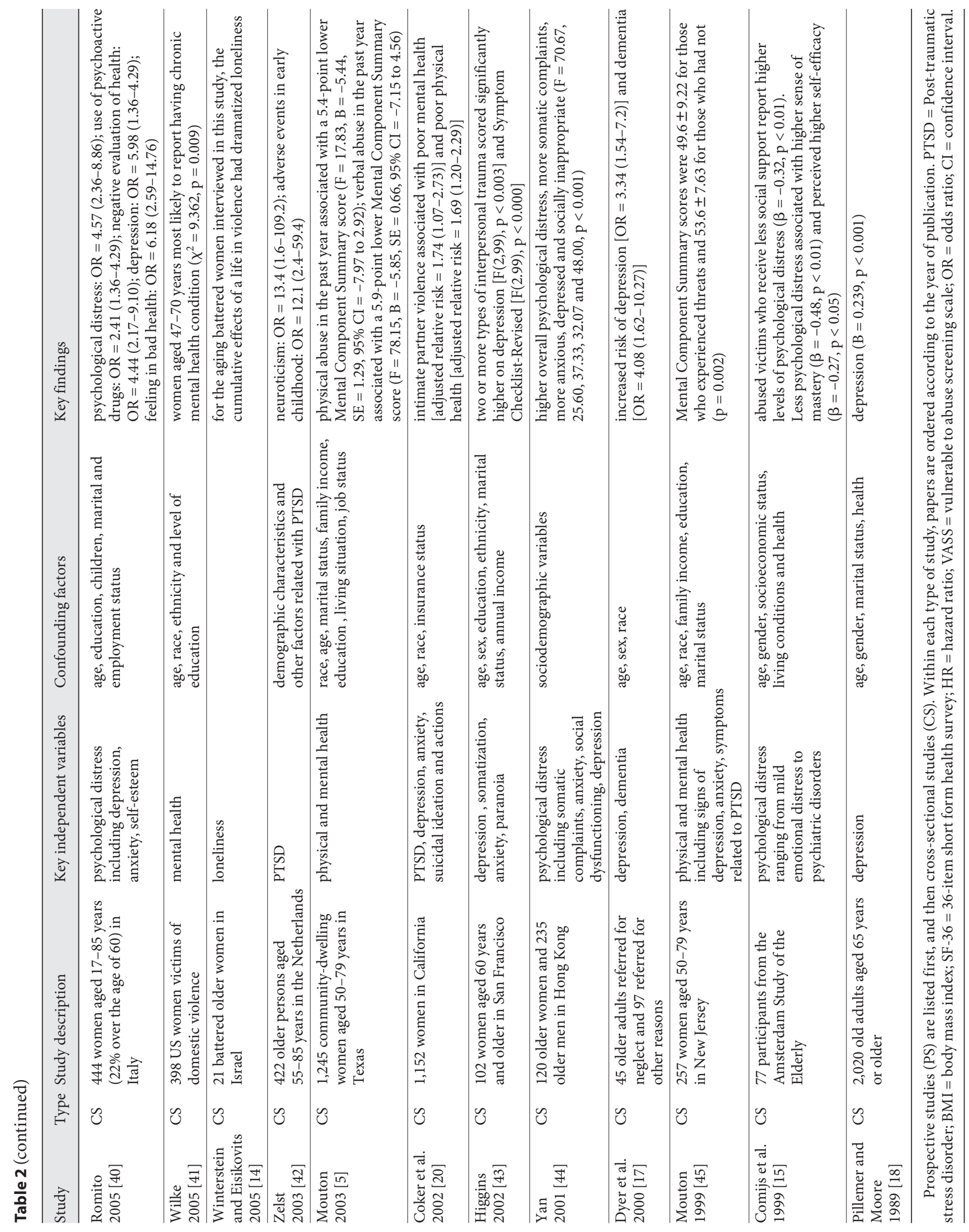


derstanding of the longitudinal relationship of the psychological consequences associated with elder abuse.

Depression, anxiety and posttraumatic disorder were reported as the most prevalent psychological consequences of elder abuse. Compared to nonvictims, abused older adults were more likely to report a higher level of psychological distress $[15,16]$. Drawing on a large epidemiological cohort, Dong et al. [13] found that elder abuse reported to a social services agency was associated with the lowest level of psychological well-being. Clinical studies also suggest that there are negative psychological health outcomes of elder abuse. Case-control studies examining the clinical profile of abused older people demonstrated that both depression and dementia are common among neglected patients referred to a public geriatric clinic [17]. Pillemer and Moore [18] also indicated that elder abuse was a strong predictor of depression.

The level of psychological distress differs according to the frequency and type of abuse and violence $[19,20]$. Luo and Waite [16] found that older adults who suffered any abuse reported greater distress than those without elder abuse [14]. In addition, older women experiencing repeated psychological abuse or multiple types of elder abuse were more likely to present depression or anxiety [21]. The impact of abuse on psychological well-being also varies according to the type of abuse. More specifically, verbal abuse was shown to be the strongest predictor of older adults' psychological distress. Emotional abuse is also significantly associated with higher levels of psychological distress than physical abuse [22].

\section{Future Research Directions}

\section{Population Research}

Longitudinal studies in national representative populations are needed to examine the incidence of subtypes of elder abuse, neglect and exploitation in different settings (e.g. community, clinical, social service, assisted living and long-term care settings) with respect to specific psychological distress domains. While the prevalence estimates of elder abuse have improved, future research is needed to ascertain incidence estimates and correlations with different subtypes of elder abuse through longitudinal data. Future studies need to focus specifically on psychological well-being as a potential risk/protective factor associated with the incident cases, as well as specific estimates of the strength of these relationships.

More specifically, it is critical to explore the impact of decline in psychological well-being on the risk of elder abuse, as well as the impact of elder abuse on the trajectories of psychological well-being. Systematic assessment of psychological well-being is needed with regard to the constructs of depression, loneliness, anxiety, perceived stress, hopelessness, suicidal thoughts and other clinical psychiatric conditions. Equally important, assessment of these relationships requires the investigators to specifically consider the effect size and take into account a wide range of potential confounders and mediators.

Systematic research is also needed to examine the psychological well-being of the potential perpetrators, and the characteristics, relations, settings and contexts with respect to elder abuse victims. Traditionally, it has been very difficult for researchers to enroll and survey the potential perpetrator(s) for scientific research, especially regarding their psychological well-being. In addition, potential perpetrators of elder abuse may or may not live in the same household and/or geographic areas as suspected elder abuse victims. Moreover, sometimes when abusive acts occur, there is no way to identify or track the potential perpetrator(s), especially in the case of financial exploitation and gray-line boundaries between caregiver neglect and self-neglect.

Despite these barriers, evidence suggests that caregivers of those with dementia have been willing to answer elder abuse questions. It is estimated that more than $40 \%$ of caregivers have admitted to some form of elder abuse, especially in the context of caregiver stress, burnout, depression and low levels of caregiving skills for vulnerable older adults. The fields of child abuse and domestic violence have demonstrated the feasibility of conducting research on potential perpetrator(s), and the field of elder abuse needs to continue pushing for innovative methods to understand the potential perpetrators' perspectives in relation to elder abuse. This information will have direct relevance to the future design and conduct of prevention and intervention studies.

Currently, our knowledge about the consequences or adverse health outcomes associated with elder abuse remains incomplete. Systematic research is needed to understand the morbidity and mortality associated with specific subtypes of elder abuse in relation to the trajectories of psychological distress. Moreover, future research is needed to quantify the influence of elder abuse subtypes on healthcare service use, especially mental and behavioral services, in representative populations. Rigorous research is needed to elucidate the risk, rate and intensity of use of these healthcare services with respect to elder abuse and its specific subtypes. Furthermore, economic analyses are needed to quantify the measurable and un- 
measureable costs associated with elder abuse and specific subtypes. As many cost-benefit economic analyses are significantly biased toward older adults, innovative strategies are needed to capture the wide range of personal, familial, community, financial and societal costs associated with elder abuse.

\section{Leverage of Existing Longitudinal Studies}

While a nationally representative longitudinal cohort focused on the issues of elder abuse is needed, it will likely be time consuming and significantly costly to achieve. The field of elder abuse needs to continue working closely with existing longitudinal aging studies to add elderabuse-specific questions into these cohorts, many of which already collect detailed data on the different domains of psychological well-being. These longitudinal studies may include the Health and Retirement Study, National Social Health Aging Project, Chicago Health and Aging Project, Established Populations for the Epidemiologic Studies of Elderly, Cardiovascular Health Study and the National Health Aging Trends Study. However, there are vast methodological complexities and issues within these longitudinal studies that will make synchronization and harmonization of data collection and funding difficult. Coordinated efforts are needed from a collective body of researchers and practitioners, but particularly from public and private funding agencies and important stakeholders interested in the issues of elder abuse.

The field of elder abuse should continue to advocate linkage of datasets between existing population-based cohorts and administrative APS datasets. Prior experiences with the New Haven Established Populations for the Epidemiologic Studies of Elderly and Chicago Health and Aging Project studies have demonstrated feasibility and success in understanding the relationship between elder abuse and psychological distress. In addition, these data linkages have contributed greatly to the knowledge base of the cross-sectional as well as longitudinal psychological risk factors associated with elder abuse. This approach has provided pivotal data on the adverse mental health outcomes associated with elder abuse, which have served as a firm foundation to push for practice and policy changes at the national level. Despite the potential limitations of using reported elder abuse cases from the APS database, benefits will likely continue to outweigh the limitations until a national representative study of elder abuse is available. Furthermore, as many longitudinal cohorts are linked to other administrative datasets (e.g. police data, center for medicare and medicaid services data), these additional data linkages could serve as pow- erful tools to conduct hypothesis testing and advance the field of elder abuse.

\section{Unification and Standardization of State APS \\ Databases}

Most states have different APS reporting and data collection systems, which creates enormous barriers to understanding the issues of elder abuse from the APS perspective at the national level. In order to gain deeper and more systematic understanding of the existing APS systems, unification and standardization of APS data collection systems and databases are critically needed. Standardization of these core elements, as well as standardization of survey procedures, could provide a more representative examination of elder abuse at the national level in the APS system. In addition, this approach would provide invaluable information about the short-term and long-term outcomes of APS investigations as well as the risk of elder abuse recidivism. Moreover, it will be important to follow these APS cases and elder abuse victims over time with respect to specific encounters with health care, social service, legal and criminal justice systems. Furthermore, unified national APS data collection could be invaluable to evaluate the needs, processes and outcomes of APS programs and interventions at the individual client's level; evaluate the current models of a multidisciplinary team; evaluate the effectiveness of current training programs for APS workers, and explore the context of the barriers for APS staff in their daily work.

\section{Interventions}

Despite the paucity of longitudinal studies, the associations between psychological distress and elder abuse highlight the need to develop intervention programs addressing both elder abuse and psychopathology. The studies and evaluations of the interventions can either be observational or randomized trials, as well as qualitative or quantitative. In general, there are three main types of interventions for elder abuse victims: advocacy service intervention, support groups and family care conference. In addition, studies have found that interventions that offer combinations of individual or family counseling, case management, skills training and behavior management strategies are more effective than interventions that only provide a support group [23]. Besides the above intervention types, healthcare professionals also make efforts to develop novel interventions addressing elder abuse. Family care conference, for instance, is a novel way to identify and find solutions to elder abuse. Family care conference 
is an elder-focused, family-centered, community-based intervention to prevent and mitigate elder abuse [24]. The strength of the family care conference intervention lies in the utilization of family power. It provides the opportunity for families to come together to discuss and solve the problem.

Research into interventions to reduce psychological distress with respect to elder abuse outcome is still in its infancy, and there exist only a limited number of interventions for psychological distress with elder abuse as a potential outcome of interest [25]. Through anger management and educational interventions, it is suggested that psychological interventions are effective to reduce the stress, anxiety and depression of perpetrators of elder abuse, which may in turn reduce the risk of elder abuse [26]. Similarly, studies also suggest that for dementia caregivers, reduction of anger and depression is positively related to caregivers' self-efficacy and belief in their ability to handle challenges [27].

There is a great paucity of evidence-based prevention and intervention strategies to assist the victims of elder abuse, especially with regard to psychological well-being. Although multidisciplinary team approaches and multicomponent interventions remain the best potential option, more systematic studies are needed. Rigorously designed intervention studies and measures of relevant outcomes for elder abuse are needed. In addition, prevention strategies are critically needed. Systematic examination of the longitudinal psychological factors as well as effect size is needed to devise targeted prevention studies. Given the extent of the different types of elder abuse and variation in risk/protective factors and perpetrator characteristics, intervention and prevention studies should begin to focus on the specific dyads which may be at particularly high risk for elder abuse. Types of prevention for potential perpetrator(s) could include anger management, coping strategies, skill training and counseling. Moreover, future prevention and intervention studies must consider the cost-effectiveness as well as the potential for scalability at the city, state or national levels.

\section{Cultural Issues}

The global aging population is increasingly diverse, and we must set national priorities to better understand the cultural issues related to elder abuse and psychological distress in diverse populations [28]. At the same time, vast heterogeneities among different cultures necessitate targeted understanding regarding in-depth cultural issues. Recent studies have expanded our knowledge of elder abuse in African-American, Latino, Korean, Indian

Elder Abuse and Psychological Well-Being and Chinese populations. Systematic quantitative and qualitative studies are needed to better define the concept and cultural variations in the construct and definition of elder abuse and its subtypes. Moreover, cultural explorations are needed to better examine the barriers to reporting elder abuse within specific sociocultural contexts. Furthermore, research is needed to explore the issues of cultural norms and cultural expectations in relation to the perception, determinants and impacts of elder abuse and psychological well-being in different racial/ethnic populations.

However, significant challenges exist in the preparation and conduct of aging research in diverse communities, especially regarding culturally sensitive issues such as psychological well-being and elder abuse. The community-based participatory research (CBPR) approach could be a potential model to explore the issues of elder abuse and psychological well-being in different racial/ethnic communities. CBPR necessitates equal partnerships between academic institutions, community organizations and key stakeholders to examine the relevant issues. These partnerships require reciprocal transfer of expertise and needs to build infrastructure towards sustainability. Recent elder abuse research in the Chicago Chinese community has demonstrated success and has enhanced infrastructure and networks for communityengaged research and community-academic partnerships. CBPR could be a novel model for conducting systematic and culturally appropriate research in diverse populations.

\section{Emerging Areas of Research}

Despite the research gaps in the field of elder abuse, it is important to begin considering translational research. Preliminary work has begun to examine the association between self-neglect and biological markers (e.g. vitamin deficiencies, inflammatory markers). In addition, evidence suggests that elder abuse is associated with cardiovascular-related mortality. This important finding should set the cornerstone for future developmental studies to elucidate the relationship between elder abuse and psychological well-being, biological changes and cardiovascular disease. Future studies are needed to examine the impact of elder abuse on stress biomarkers and other stress constructs such as allostatic load and the epigenetic consequences associated with elder abuse. Elucidating the biological effect associated with victimization and trauma could significantly improve the translational research relevant to elder abuse and psychological well-being.

Gerontology 2013;59:132-142 139 


\section{Practical and Policy Implications}

This review has implications for researchers, healthcare professionals, social service agencies, social workers, policy makers, community organizations and other relevant aging disciplines. This review underlines the need for public and community awareness and improved education for healthcare professionals. With the increasingly diverse aging population, understanding cultural nuances related to elder abuse and psychological distress could be critical to improve the quality of care of older adults. Advocacy and educational efforts should also focus on mental health issues in aging communities in the USA. For instance, social service agencies could contribute to facilitating the capacity of family members, friends, neighbors and trusted others to offer adequate care and prevent older adults from being isolated. Building a stronger association with people in their own community will provide emotional, social and practical support for older adults to decrease the risk of psychological distress and elder abuse.

Future efforts could be directed toward enhancing social support of older adults, particularly in the form of family support. Social service agencies and community organizations working with older adults should pay special notice to older adults' social network and quality of connectedness to adult children, intergenerational exchange and cultural expectations as well as satisfaction with family members. More specifically, social service organizations are well positioned to provide more programs as well as encourage the family to provide emotional support. In particular, working closely with family members to identify the psychological needs of older people could potentially ameliorate and reduce the severity of elder abuse. Given that the mortality risk for elder abuse is most pronounced among those with higher levels of psychological distress, there are major gaps in practice and policy dedicated to eliminating elder abuse. In order to reduce elder abuse and improve health and aging, interdisciplinary steps to set the groundwork for targeted prevention, detection and interventions are needed at both the program and legislative levels.

The Elder Justice Act (EJA) was passed as a part of the Affordable Healthcare Act, and for the first time, the EJA authorizes a federal response to the issues of elder abuse through training, services and demonstration programs. The Administration on Community Living (formally called Administration on Aging) is responsible for the implementation of the EJA as well as formation of the Elder Justice Coordinating Council and the National Advi- sory Board. More specifically, the Elder Justice Coordinating Council will be required to issue reports to describe the activities, accomplishments and challenges faced as well as to provide legislative recommendations to congressional committees. The National Advisory Board has already solicited nominations which will be required to submit reports and recommendations regarding elder justice activities.

The EJA will also be responsible for issuing human subject protection guidelines to assist researchers and establish elder abuse forensic centers. The EJA will provide grants and incentives for long-term care staffing and electronic medical records technology grants programs and will collect and disseminate annual data related to elder abuse from APS. The EJA will also be responsible for sponsoring and supporting training, services, reporting and the evaluation of elder justice programs in community and long-term care settings. The EJA has authorized USD 777 million funding over 4 years, and immediate appropriation is particularly important, as the APS will garner significant funding to bolster their direct services to victims.

Three other relevant pending legislations could significantly influence the field of elder abuse. The first is the Violence Against Women Act. Despite interest in the prevention and treatment of violence against older women, it constitutes a very small part of this legislation. Second is the Elder Abuse Victims Act, which is currently being drafted. This legislation will provide unprecedented services and protection to the victims of elder abuse at the national level. The third is the Older Americans Act (OAA), which is undergoing reauthorization this year. The OAA includes 4 specific components (Titles II, III, IV and VII) that have significant relevance to elder abuse. Among many components of the OAA, protection of older adults and elder justice-related activities are critical components that must be sustained and expanded. Comprehensive advocacy and policy efforts are needed to push for the issues of elder abuse in these legislations at the local community, city, state and federal levels [29].

\section{Conclusion}

In conclusion, elder abuse is a pervasive public health and human rights issue, yet there are major gaps in research, education and training. This review systematically examined the associations between elder abuse and psychological well-being, which is important not 
only for predicting adverse health outcomes in older adults but also for developing effective intervention strategies to address both elder abuse and psychological distress. Interdisciplinary collaborations are critically needed for health care professionals, law enforcement, social services, community organizations and other relevant fields to synergistically work toward effective prevention, screening and treatment strategies to reduce elder abuse and psychological distress and to improve health and aging.

\section{References}

$\checkmark 1$ Acierno R, Hernandez MA, Amstadter AB, Resnick HS, Steve K, Muzzy W, Kilpatrick DG: Prevalence and correlates of emotional, physical, sexual, and financial abuse and potential neglect in the United States: the National Elder Mistreatment Study. Am J Public Health 2010;100:292-297.

$\checkmark 2$ Dong X: Medical implications of elder abuse and neglect. Clin Geriatr Med 2005;21:293313.

$\checkmark 3$ Dong X, Simon M, Mendes de Leon C, Fulmer T, Beck T, Hebert L, Dyer C, Paveza G, Evans D: Elder self-neglect and abuse and mortality risk in a community-dwelling population. JAMA 2009;302:517-526.

4 Government Accountability Office: Elder justice: stronger federal leadership could enhance national response to elder abuse. 2011. http://aging.senate.gov/events/hr230kb2. pdf.

$\checkmark 5$ Mouton CP: Intimate partner violence and health status among older women. Violence Against Women 2003;9:1465-1477.

6 Dong X, Simon MA, Odwazny R, Gorbien M: Depression and elder abuse and neglect among a community-dwelling Chinese elderly population. J Elder Abuse Negl 2008; 20:25-41.

7 Dong X: A descriptive study of sex differences in psychosocial factors and elder mistreatment in a Chinese community population. Int J Gerontol 2008;2:206-214.

-8 Lachs MS, Williams C, O’Brien S, Hurst L, Horwitz R: Risk factors for reported elder abuse and neglect: a nine-year observational cohort study. Gerontologist 1997;37:469474.

$>9$ Dong X, Simon MA, Gorbien M, Percak J, Golden R: Loneliness in older Chinese adults: a risk factor for elder mistreatment. J Am Geriatr Soc 2007;55:1831-1835.

$>10$ Dong X, Beck T, Simon MA: The associations of gender, depression and elder mistreatment in a community-dwelling Chinese population: the modifying effect of social support. Arch Gerontol Geriatr 2010;50: 202-208.

-11 Natan MB, Lowenstein A, Eisikovits Z: Psycho-social factors affecting elders' maltreatment in long-term care facilities. Int Nurs Rev 2010;57:113-120.
12 Williamson GM, Shaffer DR: Relationship quality and potentially harmful behaviors by spousal caregivers: how we were then, how we are now. The Family Relationships in Late Life Project. Psychol Aging 2001;16:217-226.

13 Dong XQ, Simon MA, Beck TT, Farran C, McCann JJ, Mendes de Leon CF, Laumann E, Evans DA: Elder abuse and mortality: the role of psychological and social wellbeing. Gerontology 2011;57:549-558.

14 Winterstein T, Eisikovits Z: The experience of loneliness of battered old women. J Women Aging 2005;17:3-19.

15 Comijs HC, Penninx BW, Knipscheer KP, van TW: Psychological distress in victims of elder mistreatment: the effects of social support and coping. J Gerontol B Psychol Sci Soc Sci 1999;54:P240-P245.

16 Luo Y, Waite LJ: Mistreatment and psychological well-being among older adults: exploring the role of psychosocial resources and deficits. J Gerontol B Psychol Sci Soc Sci 2011;66:217-229.

17 Dyer CB, Pavlik VN, Murphy KP, Hyman DJ: The high prevalence of depression and dementia in elder abuse or neglect. J Am Geriatr Soc 2000;48:205-208.

18 Pillemer K, Moore DW: Abuse of patients in nursing homes: findings from a survey of staff. Gerontologist 1989;29:314-320.

19 Begle AM, Strachan M, Cisler JM, Amstadter $\mathrm{AB}$, Hernandez M, Acierno R: Elder mistreatment and emotional symptoms among older adults in a largely rural population: the South Carolina elder mistreatment study. J Interpers Violence 2011;26:2321-2332.

20 Coker AL, Davis KE, Arias I, Desai S, Sanderson M, Brandt HM, Smith PH: Physical and mental health effects of intimate partner violence for men and women. Am J Prev Med 2002;23:260-268.

21 Fisher BS, Regan SL: The extent and frequency of abuse in the lives of older women and their relationship with health outcomes. Gerontologist 2006;46:200-209.

22 Pico-Alfonso MA, Garcia-Linares MI, Celda-Navarro N, Blasco-Ros C, Echeburua E, Martinez M: The impact of physical, psychological, and sexual intimate male partner violence on women's mental health: depressive symptoms, posttraumatic stress disorder, state anxiety, and suicide. J Womens Health (Larchmt) 2006;15:599-611.
23 Beach SR, Schulz R, Williamson GM, Miller LS, Weiner MF, Lance CE: Risk factors for potentially harmful informal caregiver behavior. J Am Geriatr Soc 2005;53:255-261.

24 Holkup PA, Salois EM, Tripp-Reimer T, Weinert C: Drawing on wisdom from the past: an elder abuse intervention with tribal communities. Gerontologist 2007;47:248254

25 Papadopoulos A, La Fontaine J: Elder Abuse: Therapeutic Perspectives in Practice. Bicester, Winslow, 2000.

$>26$ Reay AMC, Browne KD: The effectiveness of psychological interventions with individuals who physically abuse or neglect their elderly dependents. J Interpers Violence 2002;17: 416-431.

27 Steffen AM: Anger management for dementia caregivers: a preliminary study using video and telephone interventions. Behav Ther 2000;31:281-299.

28 Dong X, Chang E-S, Wong E, Wong B, Simon MA: How do U.S. Chinese older adults view elder mistreatment? Findings from a community-based participatory research study. J Aging Health 2011;23:289-312.

29 Dong X, Simon MA: Enhancing national policy and programs to address elder abuse. JAMA 2011;305:2460-2461.

-30 Cooper C, Blanchard M, Selwood A, Walker Z, Livingston G: Family carers' distress and abusive behaviour: longitudinal study. Br J Psychiatry 2010;196:480-485.

-31 Cooper C, Katona C, Finne-Soveri H, Topinkova E, Carpenter GI, Livingston G: Indicators of elder abuse: a crossnational comparison of psychiatric morbidity and other determinants in the Ad-HOC study. Am J Geriatr Psychiatry 2006;14:489-497.

32 Fulmer T, Paveza G, Vandeweerd C, Fairchild S, Guadagno L, Bolton-Blatt $\mathrm{M}$ et al: Dyadic vulnerability and risk profiling for elder neglect. Gerontologist 2005;45:525534.

33 Choi NG, Mayer J: Elder abuse, neglect, and exploitation. J Gerontol Soc Work 2000;33: 5-25.

34 Steinmetz SK: Elder abuse by adult offspring. the relationship of actual vs. perceived dependency. J Health Hum Resour Adm 1990; 12:434-463. 
35 Schofield MJ, Mishra GD: Three year health outcomes among older women at risk of elder abuse: women's health Australia. Qual Life Res 2004;13:1043-1052.

- 36 Hill TD, Kaplan LM, French MT, Johnson RJ: Victimization in early life and mental health in adulthood: an examination of the mediating and moderating influences of psychosocial resources. J Health Social Behav 2010;51: 48-63.

37 Amstadter AB, Begle AM, Cisler JM, Hernandez MA, Muzzy W, Acierno R: Prevalence and correlates of poor self-rated health in the United States: the national elder mistreatment study. Am J Geriatr Psychiatry 2010;18:615-623.
38 Baker MW, LaCroix AZ, Wu C, Cochrane BB, Wallace R, Woods NF: Mortality risk associated with physical and verbal abuse in women aged 50 to 79. J Am Geriatr Soc 2009; 57:1799-1809.

39 Acierno R, Lawyer SR, Rheingold A, Kilpatrick DG, Resnick HS, Saunders BE: Current psychopathology in previously assaulted older adults. J Interpers Violence 2007;22: 250-258.

40 Romito P, Molzan Turan J, De Marchi M: The impact of current and past interpersonal violence on women's mental health. Soc Sci Med 2005;60:1717-1727.

41 Wilke DJ, Vinton L: The nature and impact of domestic violence across age cohorts. Affilia 2005;20:316-328.

-42 van Zelst WH, de Beurs E, Beekman AT, Deeg DJ, van Dyck R: Prevalence and risk factors of posttraumatic stress disorder in older adults. Psychother Psychosom 2003;72: 333-342.
43 Higgins A, Follette V: Frequency and impact of interpersonal trauma in older women. Journal of Clinical Geropsychology 2002;8: 215-226.

44 Yan E, Tang C: Prevalence and psychological impact of chinese elder abuse. J Interpers Violence 2001;16:1158-1174.

45 Mouton CP, Rovi S, Furniss K, Lasser NL: The associations between health and domestic violence in older women: results of a pilot study. J Womens Health Gend Based Med 1999;8:1173-1179.

46 Dong X, Beck T, Simon MA: Loneliness and mistreatment of older Chinese women: does social support matter? Women Aging 2009; 21:293-302. 